\title{
Corrosion Behaviour of Metals in Artificial Sweat
}

\author{
R. Joseph Rathish ${ }^{1}$, S. Rajendran ${ }^{*}, 2,3$, J. Lydia Christy ${ }^{4}$, B. Shyamala Devi ${ }^{5}$, S. Johnmary ${ }^{6}$, \\ M. Manivannan ${ }^{7}$, K. Rajam ${ }^{8}$ and P. Rengan ${ }^{9}$
}

\author{
${ }^{I}$ Department of EEE, PSNA College of Engineering and Technology, Kothandaraman Nagar, Dindigul, Tamil Nadu, \\ India \\ ${ }^{2}$ Servite College of Education for Women, Thogaimalai-621313, Tamil Nadu, India \\ ${ }^{3}$ Corrosion Research Centre, Post Graduate and Research Department of Chemistry, GTN Arts College, Dindigul- \\ 624005, India \\ ${ }^{4}$ Department of Chemistry, VSB Engineering College, Karur-639111, Tamil Nadu, India \\ ${ }^{5}$ Department of Chemistry, Vivekanandha Institute of Engineering and Technology, Thiruchengode, Tamil Nadu, India \\ ${ }^{6}$ Department of Chemistry, Loyola College, Chennai, India \\ ${ }^{7}$ Department of Chemistry, Chettinad College of Engineering and Technology, Karur, Tamil Nadu, India \\ ${ }^{8}$ Department of Chemistry, KLN College of Information Technology, Pottapalayam, Sivaganga District, Tamil Nadu, \\ India \\ ${ }^{9}$ Department of Chemistry, Yadava College, Madurai, Tamil Nadu, India
}

\begin{abstract}
Human sweat comes in contact with a number of consumer products. This results in a variety of undesirable effects such as corrosion and malfunction. Corrosion behaviour of three metals, namely, mild steel (MS), galvanized steel (GS) and SS $316 \mathrm{~L}$ in artificial sweat (the ISO standard ISO 3160-2) has been studied by polarization study and AC impedance spectra. The study reveals that the decreasing order of corrosion resistance is SS $316 \mathrm{~L}>\mathrm{MS}>\mathrm{GS}$.
\end{abstract}

Keywords: Corrosion of metals, artificial sweat, SS 316 L, mild steel.

\section{INTRODUCTION}

Human perspiration (sweat) comes in contact with a number of consumer products. Contact can cause a variety of undesirable effects. Dyes can bleed or discolour, components can corrode and/or malfunction, residues can be unsightly.

The problem of metal corrosion resulting from contamination by palmar sweat is common to many industrial occupations. Constant handling of metal parts by some individuals causes an accumulation of rust. In the manufacture of highly finished metal products, for example ball-bearings, and also in subsequent assembling and packing processes, serious consideration must be given to this effect [1].

The corrosive nature of sweat has been known as early as 1919. But few objective investigations on this subject have appeared. Metal ion release from electric guitar strings in artificial sweat has been investigated [2]. Electric guitar strings consisted of two separate parts: Sn-plated steel core wire which has hexagonal in cross section and Ni-plated steel wrap which was round in cross section. Dissolution of $\mathrm{Ni}^{2+}, \mathrm{Si}^{4+}, \mathrm{Mn}^{2+}, \mathrm{Sn}^{2+}$ and $\mathrm{Fe}^{3+}$ ions from electric guitar strings E6 and D4 were measured as a function of time in

*Address correspondence to this author at the Servite College of Education for Women, Thogaimalai-621313, Tamil Nadu, India, Tel: 91 4512424114, 914323290752; Fax: 91 4323252263;

E-mail: srmjoany@sify.com artificial sweat solution. Among all investigated metal ions, nickel is far the most allergenic.

Corrosion behaviours of electroless plating Ni-P coatings deposited on magnesium alloys in artificial sweat solution have been studied [3]. Magnesium alloys are the optimum shell materials for electronic products. These electronic products inevitably contact with the hands of the user and then are corroded by the sweat solution mainly consisting $0.1 \%$ urea, $0.5 \% \mathrm{NaCl}$ and $0.5 \%$ lactic acid. Electroless plating Ni-P coatings can provide protection to the magnesium alloys shell. The study indicated that urea acted as corrosion inhibitor. The inhibiting effect of urea was reduced in $\mathrm{NaCl}$ solution or lactic acid solution. Randian [4] has evaluated the corrosion resistance of nickel in artificial sweat and synthetic seawater. The corrosion resistance of nickel 200 has been determined in artificial sweats (perspiration) and in synthetic seawater by several electrochemical methods. Nickel 200 is not stable in the two electrolytes investigated and the attack occurs with the formation of pits. Nickel 200 cannot be used for application where it may be in direct contact with the skin because of its high corrosion rate in oxygenated sweat. The released nickel ion is responsible for contact dermatitis observed in some individuals.

Skin exudates can corrode (oxidize) and possibly dissolve metal surfaces they contact. Their composition varies as a function of physical, pharmacological and 
environmental conditions, gender, age, sweat rate, body site and methods of collection, also in a healthy organism [5].

The corrosion resistance of various nickel-containing alloys was measured in artificial sweat (perspiration) using the Tafel extrapolation method. It was found that $\mathrm{Ni}, \mathrm{CuNi}$ 25 (coin alloy), NiAl (colored intermetallic compounds), $\mathrm{WC}+\mathrm{Ni}$ (hard metal), white gold (jewelry alloy), FN42 and Nilo Alby K (controlled expansion alloys), and NiP (electroless nickel coating) are in an active state and dissolve readily in oxygenated artificial sweat. By contrast, austenitic stainless steels, $\mathrm{TiC}+\mathrm{Mo}_{2} \mathrm{C}+\mathrm{Ni}$ (hard metal), NiTi (shapememory alloy), Hastelloy $\chi$ (superalloy), Phydur (precipitation hardening alloy), $\mathrm{PdNi}$ and $\mathrm{SnNi}$ (nickel-containing coatings) are in a passive state but may pit under certain conditions. Cobalt, $\mathrm{Cr}, \mathrm{Ti}$, and some of their alloys were also investigated for the purpose of comparison. Cobalt and its alloys have poor corrosion resistance except for Stellite 20. Chromium and high-chromium ferritic stainless steels have a high pitting potential but the latter are susceptible to crevice corrosion [6].

Copper and its alloys are subject to chemical reactions on exposure to environmental or physiological factors, whereby products are potentially generated which become diffusible through mammalian skin. The chemistry of oxidation is reviewed as well as the factors contributing to corrosion. Skin exudates (sweat and sebum) can react with metal surfaces they come in contact with, but even in the healthy organism their composition is variable, as a function of physical, pharmacological and environmental conditions, gender, age, sweat rate or body site. This overview addresses sweat and sebum composition, and discusses components which determine the skin's corrosive action: chloride ion, low-molecular-weight acids and amino acids in sweat, and fatty acids in sebum, which hold the potential to solubilize copper-containing metal objects. These components can form copper salts and soaps whose molecular characteristics (size and polarity) will determine the rate and route of cutaneous penetration [7].

The present work is undertaken to study the corrosion behaviour of three metals, namely, mild steel, galvanized steel and SS $316 \mathrm{~L}$, in artificial sweat by polarization study and $\mathrm{AC}$ impedance spectra. Corrosion parameters such as corrosion potential, corrosion current, linear polarization resistance, charge transfer resistance and double layer capacitance have been derived from these studies.

\section{MATERIALS AND METHODOLOGY}

Three metal specimens, namely, mild steel, mild steel coated with zinc (commercial galvanized steel) and SS316L were chosen for the present study. The composition of mild steel is (wt \%) $0.026 \mathrm{~S}, 0.06 \mathrm{P}, 0.4 \mathrm{Mn}, 0.1 \mathrm{C}$ and balance iron [8]. The composition of SS316L is (wt \%): $18 \mathrm{Cr}, 12 \mathrm{Ni}$, $2.5 \mathrm{Mo},<0.03 \mathrm{C}$ and balance iron [9]. The metal specimens were encapsulated in Teflon. The surface area of the exposed metal surface was $0.00785 \mathrm{~cm}^{2}$. The metal specimens were polished to mirror finish and degreased with trichloroethylene. The metal specimens were immersed in artificial sweat (the ISO standard ISO 3160-2), whose composition was : $20 \mathrm{~g} / 1 \mathrm{NaCl}, 17.5 \mathrm{~g} / 1 \mathrm{NH}_{4} \mathrm{Cl}, 5 \mathrm{~g} / 1$ acetic acid and $15 \mathrm{~g} / \mathrm{l}$ d,1 lactic acid with the $\mathrm{pH}$ adjusted to 4.7 by $\mathrm{NaOH}$.

In electrochemical studies, the metal specimens were used as working electrodes. Artificial sweat (AS) was used as the electrolyte $(10 \mathrm{ml})$. The temperature was maintained at $37 \pm 0.1^{\circ} \mathrm{C}$.

\section{Potentiodynamic Polarization}

Polarization studies were carried out in a CHI Electrochemical workstation with impedance, Model 660A. A three-electrode cell assembly was used. The working electrode was one of the three metals. A saturated calomel electrode (SCE) was the reference electrode and platinum was the counter electrode. The details of the experimental conditions are as follows: Hold Time at $\mathrm{Ef}(\mathrm{s})=0$; Scan Rate $(\mathrm{v} / \mathrm{s})=0.005$; Quiet Time $(\mathrm{s})=2$.

From the polarization study, corrosion parameters such as corrosion potential $\left(\mathrm{E}_{\text {corr }}\right)$, corrosion current $\left(\mathrm{I}_{\text {corr }}\right)$ and Tafel slopes (anodic $=b_{a}$ and cathodic $=b_{c}$ ) and linear polarization resistance (LPR) were calculated. LPR monitoring is an effective electrochemical method of measuring corrosion. Monitoring the relationship between electrochemical potential and current generated between electrically charged electrodes in a process stream allows the calculation of corrosion current. If the electrodes are corroding at high rate with the metal ions passing into solution, a small potential applied between the electrodes will produce a high current, and therefore a low polarization resistance. This corresponds to a high corrosion rate $[10,11]$.

\section{AC Impedance Spectra}

The instrument used for polarization study was used to record AC impedance spectra also. The cell setup was also the same. The real part (Z') and imaginary part (Z') of the cell impedance were measured in ohms at various frequencies. The details of the experimental conditions are as follows: Initial $\mathrm{E}(\mathrm{V})=0$; High frequency $(\mathrm{Hz})=1 \times 10^{5}$; Low frequency $(\mathrm{Hz})=10$; Amplitude $(\mathrm{V})=0.005$; Quiet Time $(s)=2$. Values of the charge transfer resistance $\left(R_{t}\right)$ and the double layer capacitance $\left(\mathrm{C}_{\mathrm{dl}}\right)$ were calculated.

\section{RESULTS AND DISCUSSION}

\section{Potentiodynamic Polarization Study}

The potentiodynamic polarization curves of various metals (MS, GS and SS 316 L) immersed in artificial sweat solution is shown in Figs. (1-3). The corrosion parameters, namely, corrosion potential $\left(\mathrm{E}_{\mathrm{corr}}\right)$, Tafel slopes $\left(\mathrm{b}_{\mathrm{c}}=\right.$ cathodic; $\mathrm{b}_{\mathrm{a}}=$ anodic), linear polarization resistance (LPR) and corrosion current $\left(\mathrm{I}_{\text {corr }}\right)$ are given in Table $\mathbf{1}$.

When mild steel (MS) is immersed in AS solution (Fig. 1) the corrosion potential is $-704 \mathrm{mV} v s$ SCE. The cathodic Tafel slope $\left(b_{c}\right)$ is $328 \mathrm{mV} /$ decade and the anodic Tafel slope is $87 \mathrm{mV} /$ decade. It is inferred that the change of current with change in potential is less during anodic polarization than during cathodic polarization. The LPR value is $2.138 \mathrm{x}$

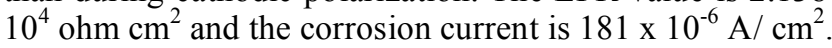

When galvanized steel (GS) is immersed in AS solution (Fig. 2). The corrosion potential is shifted to the noble side (anodic side, $-412 \mathrm{mV}$ vs $\mathrm{SCE}$ ) (relative to $\mathrm{MS}$ ). This suggests that a protective film is formed on the metal 
Table 1. Corrosion Parameters of Metals Immersed Artificial Sweat (AS) Obtained from Polarization Study

\begin{tabular}{|c|c|c|c|c|c|}
\hline Metal & $\mathbf{E}_{\text {corr }} \mathbf{m V}$ vs SCE & $\begin{array}{c}\mathbf{b}_{\mathbf{c}} \\
\mathbf{m V} / \mathbf{D e c a d e}\end{array}$ & $\begin{array}{c}\mathbf{b}_{\mathbf{a}} \\
\mathbf{m V} / \mathbf{D e c a d e}\end{array}$ & $\begin{array}{c}\text { LPR } \\
\mathbf{o h m} \mathbf{c m}^{2}\end{array}$ & $\begin{array}{c}\mathbf{I}_{\text {corr }} \\
\mathbf{A} / \mathbf{c m}^{2}\end{array}$ \\
\hline \hline MS + AS & -704 & 328 & 89 & $2.138 \times 10^{4}$ & $181 \times 10^{-6}$ \\
\hline GS + AS & -412 & 128 & 126 & $6.568 \times 10^{6}$ & $877 \times 10^{-9}$ \\
\hline SS 316 L + AS & -443 & 134 & 665 & $5.054 \times 10^{5}$ & $1224 \times 10^{-8}$ \\
\hline
\end{tabular}

surface. The cathodic and anodic Tafel slops are almost equal (128 and $126 \mathrm{mV} /$ decade). This indicates that the change of current during change of potential is more or less equal during anodic and cathodic polarization.

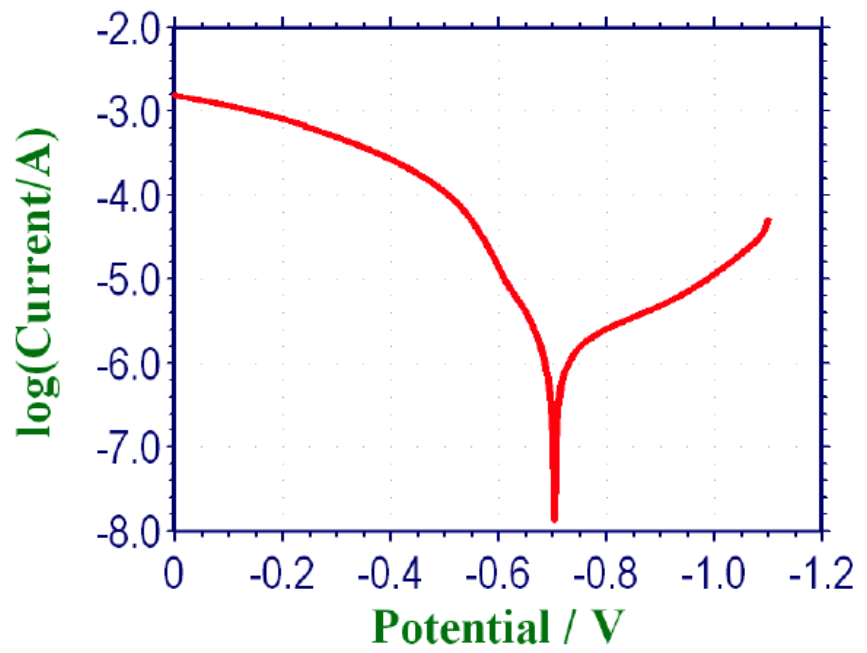

Fig. (1). Polarization curve of MS immersed in artificial sweat.

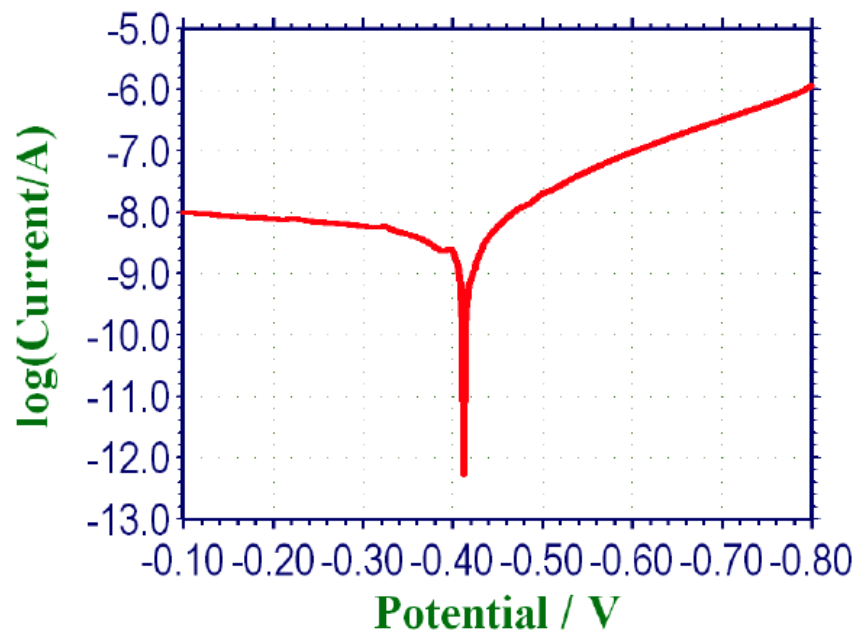

Fig. (2). Polarization curve of GS immersed in artificial sweat.

The LPR value increases from $2.138 \times 10^{4}$ to $6.568 \times 10^{6}$ $\mathrm{ohm} \mathrm{cm}^{2}$. The corrosion current value decreases from $181 \mathrm{x}$ $10^{-6}$ to $877 \times 10^{-9} \mathrm{~A} / \mathrm{cm}^{2}$. These results suggest that mild steel coated with zinc is more corrosion resistant than mild steel. This may be due to the cathodic protective nature of zinc. Zinc undergoes corrosion protecting mild steel. Zinc is often referred to as sacrificial anode [12].

When SS $316 \mathrm{~L}$ is immersed in AS solution, the corrosion potential is shifted to $-443 \mathrm{mV}$ vs SCE (Fig. 3). It is anodic (noble) when compared with mild steel and it is cathodic (active) when compared with mild steel coated with zinc. That is, SS $316 \mathrm{~L}$ is more corrosion resistant than mild steel and less corrosion resistant than mild coated with zinc. This view is supported by the fact that the LPR value is $5.054 \times 10^{5} \mathrm{ohm} \mathrm{cm}^{2}$, when SS $316 \mathrm{~L}$ is immersed in AS solution. This value is higher when compared with the value of mild steel and it is lower when compared with the value of mild steel coated with zinc. This is further supported by the corrosion current value $\left(1224 \times 10^{-8} \mathrm{~A} / \mathrm{cm}^{2}\right)$, which is lower than that of mild steel and which is higher than that of mild steel coated with zinc. An increase in LPR value and a decrease in corrosion current value are indications of more corrosion resistant nature of a metal in a medium. It is observed that the value of current remains almost constant in the potential range -382 to $-100 \mathrm{mV}$ vs SCE. This indicates that the film formed on the metal surface is stable in this potential range. Then the film is broken and the current passing through the metal increases.

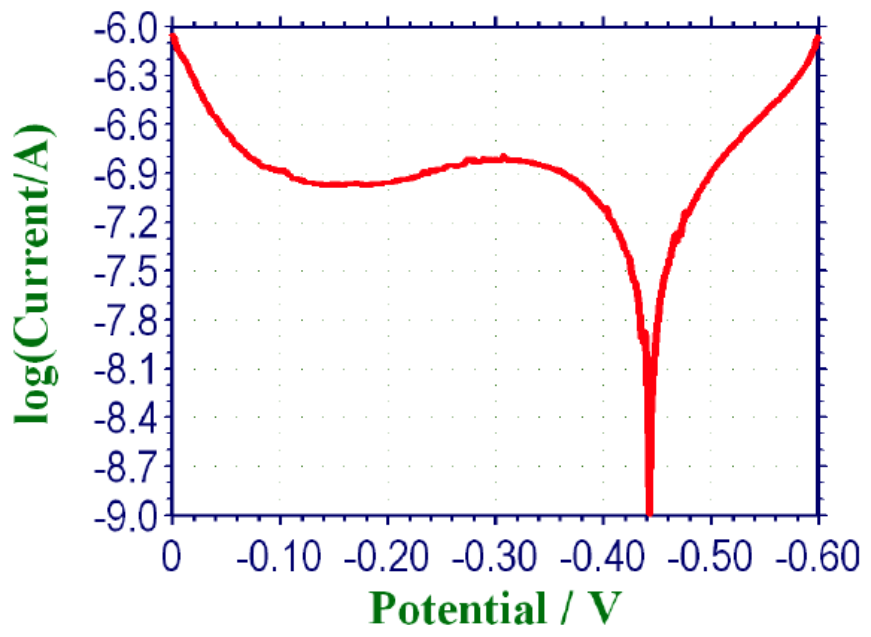

Fig. (3). Polarization curve of SS $316 \mathrm{~L}$ immersed in artificial sweat.

Polarization study leads to the conclusion that the decreasing order of corrosion resistance in artificial sweat is $\mathrm{GS}>\mathrm{SS} 316 \mathrm{~L}>\mathrm{MS}$.

\section{AC Impedance Spectra}

AC impedance spectra of metals immersed in artificial sweat (AS) solution are shown in Figs. (4-12). Nyquist plots are shown in Figs. (4-6) and the bode plots are shown in Figs. (7-12). The charge transfer resistance $\left(R_{t}\right)$ and double layer capacitance $\left(\mathrm{C}_{\mathrm{dl}}\right)$ values (derived from Nyquist plots) and the impedance, $\log (\mathrm{Z} / \mathrm{ohm})$, values derived from bode plots are given in Table 2 .

When mild steel is immersed in AS solution, the charge transfer resistance is $217 \mathrm{ohm} \mathrm{cm}^{2}$ and the double layer capacitance is $299 \times 10^{-8} \mathrm{~F} / \mathrm{cm}^{2}$ (Fig. 4). The impedance, log (Z/ohm), value is 2.378 (Fig. 7). 
Table 2. Corrosion Parameters of Metals Immersed in Artificial Sweat Obtained from AC Impedance Spectral Study

\begin{tabular}{|c|c|c|c|}
\hline \multirow{2}{*}{ Metal } & \multicolumn{2}{|c|}{ Nyquist Plot } & Bode Plot \\
\cline { 2 - 4 } & $\begin{array}{c}\mathbf{R}_{\mathbf{t}} \\
\text { ohm cm }\end{array}$ & $\begin{array}{c}\mathbf{C}_{\mathbf{d l}} \\
\mathbf{F} / \mathbf{c m}^{2}\end{array}$ & $\begin{array}{c}\text { Impedance, } \\
\mathbf{l o g}(\mathbf{Z} / \mathbf{o h m})\end{array}$ \\
\hline \hline MS + AS & 217 & $299 \times 10^{-8}$ & 2.378 \\
\hline GS + AS & 115 & $565 \times 10^{-8}$ & 2.130 \\
\hline SS 316 L + AS & 17900 (very high) & $317 \times 10^{-10}$ & 4.799 \\
\hline
\end{tabular}

When galvanized steel is immersed in AS solution the charge transfer resistance decrease from $217 \mathrm{ohm} \mathrm{cm}^{2}$ to 115 $\mathrm{ohm} \mathrm{cm}^{2}$ and the double layer capacitance value increases from $299 \times 10^{-8}$ to $565 \times 10^{-8} \mathrm{~F} / \mathrm{cm}^{2}$ (Fig. 5). The impedance value decreases from 2.378 to 2.130 . This indicates that mild steel coated with zinc less corrosion resistant than mild steel.

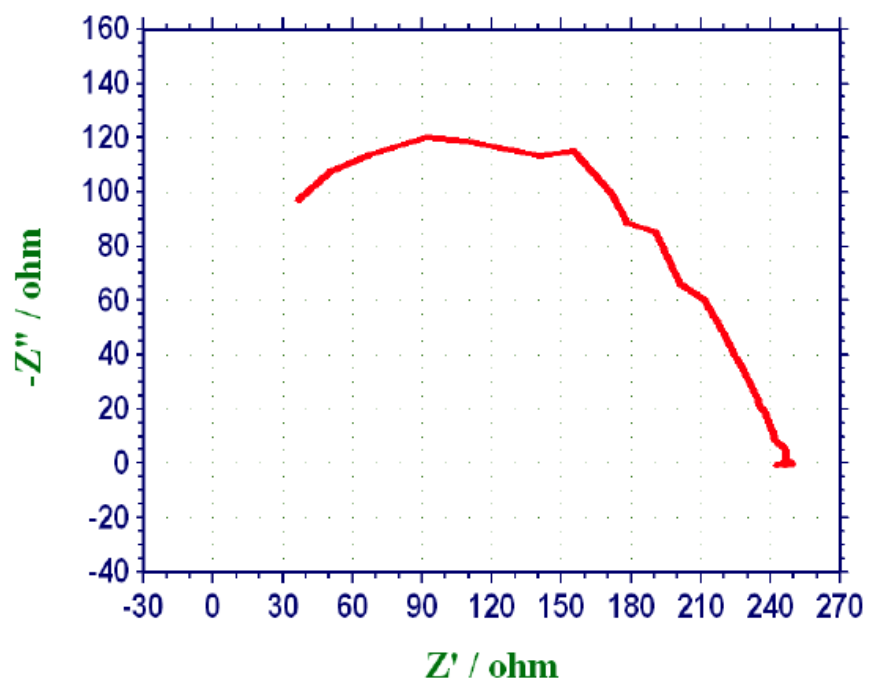

Fig. (4). AC impedance spectrum (Nyquist plot) of MS immersed in artificial sweat.

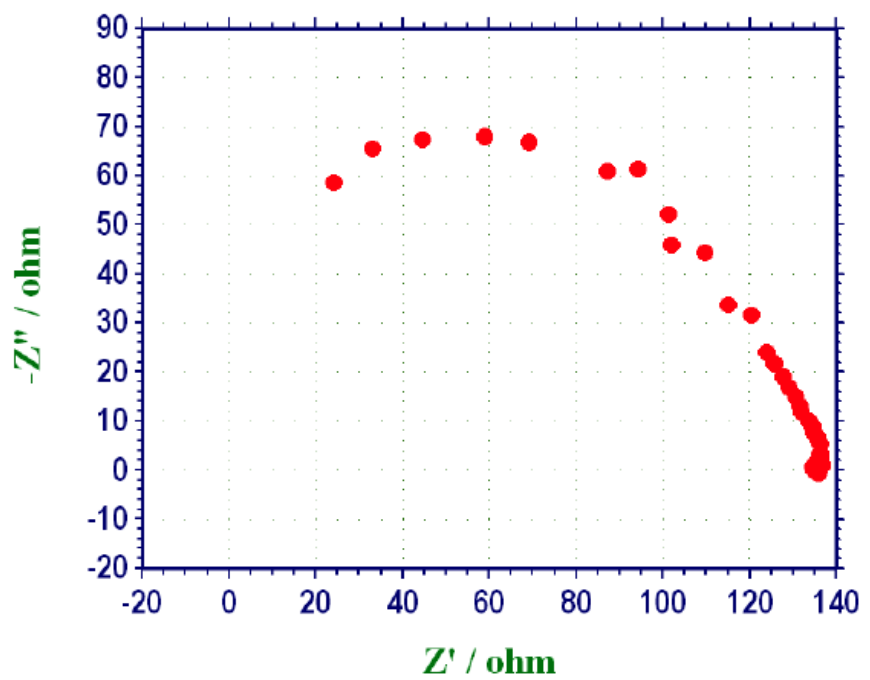

Fig. (5). AC impedance spectrum (Nyquist plot) of GS immersed in artificial sweat.

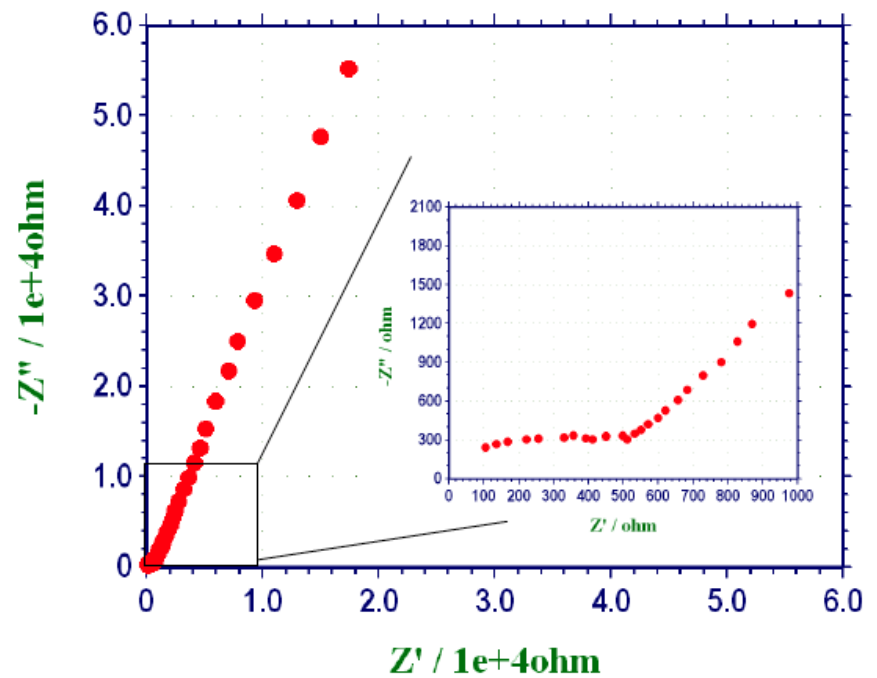

Fig. (6). AC impedance spectrum (Nyquist plot) of SS 316 L immersed in artificial sweat.

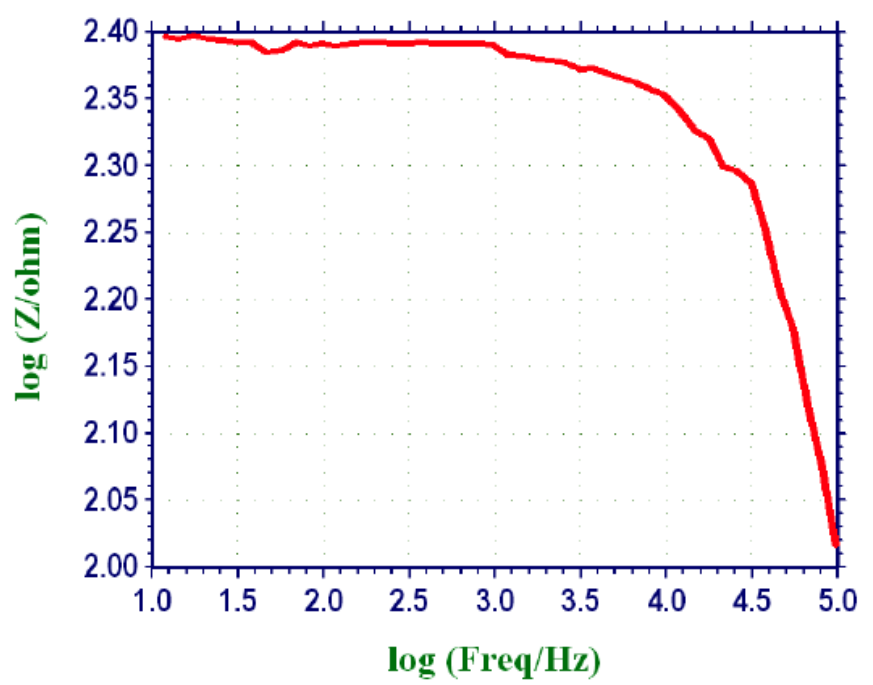

Fig. (7). AC impedance spectrum (Bode frequency plot) of MS immersed in artificial sweat.

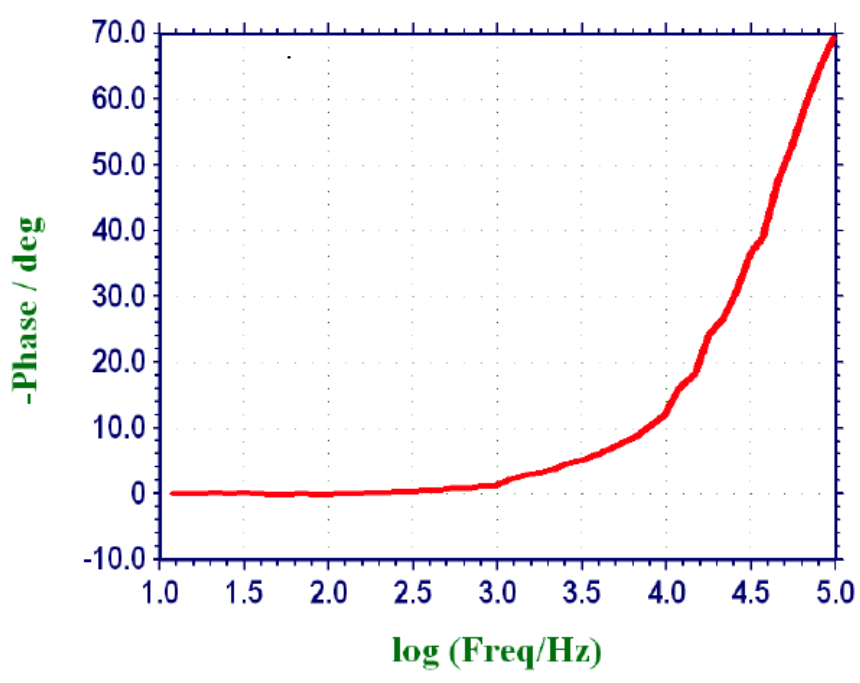

Fig. (8). AC impedance spectrum (Bode phase plot) of MS immersed in artificial sweat. 


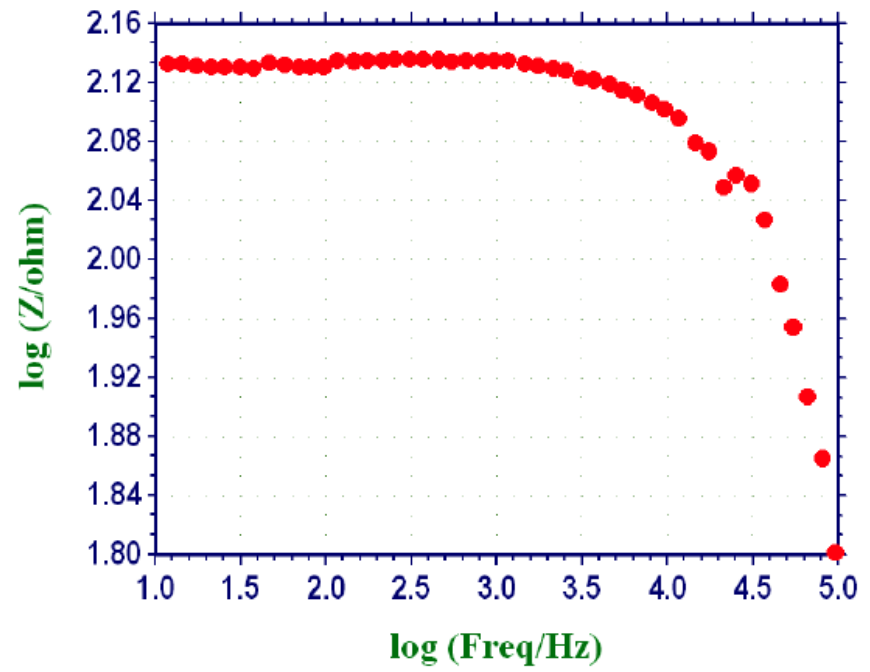

Fig. (9). AC impedance spectrum (Bode frequency plot) of GS immersed in artificial sweat.

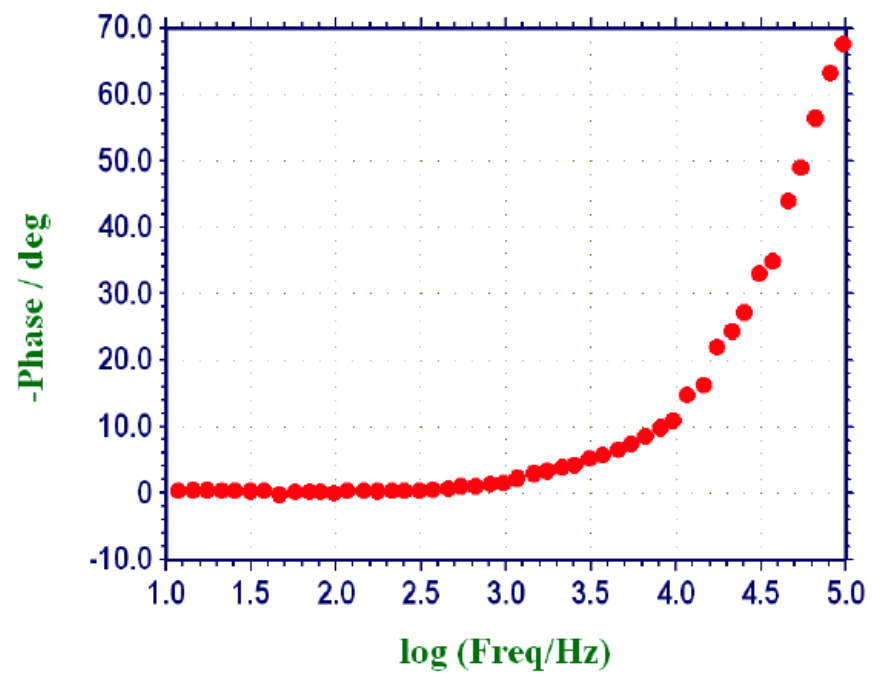

Fig. (10). AC impedance spectrum (Bode Phase plot) of MS immersed in artificial sweat.

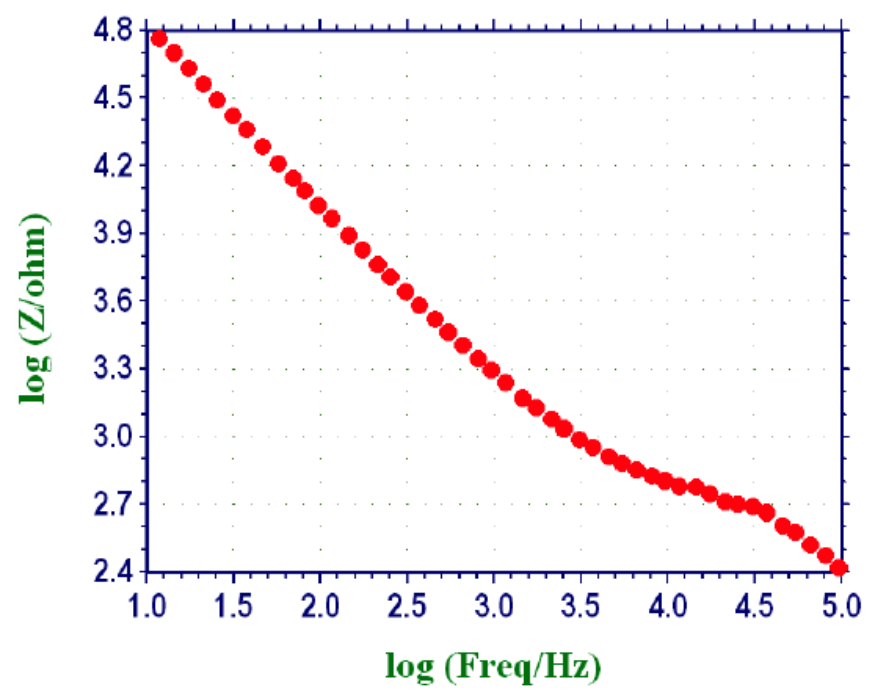

Fig. (11). AC impedance spectrum (Bode Frequency plot) of MS immersed in artificial sweat.

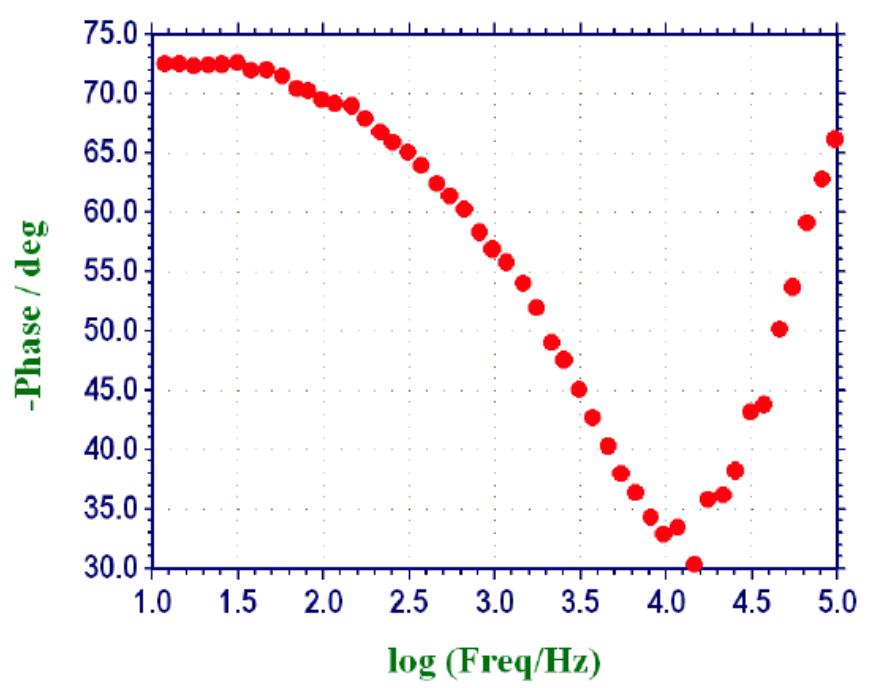

Fig. (12). AC impedance spectrum (Bode Phase plot) of MS immersed in artificial sweat.

It is interesting to note that according to polarization study, galvanized steel (GS) is more corrosion resistant than mild steel (MS). But according to AC impedance spectra, GS is less corrosion resistant than MS.

This can be explained by the fact that the film formed on the metal surface (GS) is amorphous and porous; it is broken by the aggressive ions present in the AS solution. Hence the charge transfer resistance decreases and double layer capacitance value increases.

When SS $316 \mathrm{~L}$ is immersed in AS solution the charge transfer resistance value is very high. The double layer capacitance value decreases (Fig. 6). The impedance value increases (Fig. 9). These observations indicate that SS $316 \mathrm{~L}$ is more corrosion resistant that other metals under investigation.

The very small semicircle (Fig. 5 inset) in the Nyquist plot suggests the formation of chromium oxide film on the metal surface to a very small extent. Afterwards there is no transfer of electrons from the metal surface. Hence the charger transfer resistance value is very high; the impedance value, $\log (\mathrm{Z} / \mathrm{ohm})$ is also relatively high (4.799).

Thus, AC impedance spectra lead to the conclusion that the decreasing order of corrosion resistance of metals in artificial sweat is as follows:

SS $316 \mathrm{~L}>\mathrm{MS}>\mathrm{GS}$

The difference in conclusion derived from polarization study and AC impedance spectra may be attributed by the fact that $\mathrm{AC}$ impedance spectra reveal that the closepackedness and compactness of the protective film formed on the metal surfaces is as follows SS $316 \mathrm{~L}>\mathrm{MS}>\mathrm{GS}$. The corrosion behaviour of the protective films appears to be governed by a complex interrelated ensemble of chemical, structural, textural, morphological and electronic characteristics of the films.

\section{Analysis of Bode Plots}

\section{Mild Steel in Artificial Sweat Solution}

Analysis of $\log (\mathrm{Freq} / \mathrm{Hz})$ vs $\log (\mathrm{Z} / \mathrm{ohm})$ plot reveals that when $\log ($ Freq $/ \mathrm{Hz})$ value is $1, \log (\mathrm{Z} / \mathrm{ohm})$ value is 
maximum (2.399) (Fig. 7). As the value of frequency increases, impedance value almost remains constant upto 3.0. Afterwards, as the value of frequency increases, the impedance value decreases. When the $\log (\mathrm{Freq} / \mathrm{Hz})$ is 5.0 , the $\log (\mathrm{Z} / \mathrm{ohm})$ value is minimum, namely 2.017 .

Analysis of $\log (\mathrm{Freq} / \mathrm{Hz})$ vs -phase/deg reveals that the value of -phase/deg remains at zero upto $\log (\mathrm{Freq} / \mathrm{Hz})$ value of 3.0 (Fig. 8). Then upto 4.0, it slowly increases. Afterwards, a sudden increase is noticed. The maximum phase/deg is 70.0 when $\log ($ Freq/Hz) is 5.0.

\section{Galvanized Steel in Artificial Sweat Solution}

Analysis of $\log (\mathrm{Freq} / \mathrm{Hz})$ vs $\log (\mathrm{Z} / \mathrm{ohm})$ plot reveals that when $\log ($ Freq $/ \mathrm{Hz})$ value is 1.0 , the value of $\log (\mathrm{Z} / \mathrm{ohm})$, (impedance), is highest (2.130) (Fig. 9). It almost remains constant upto 3.0. Afterwards the impedance value slowly decreases upto 4.0. Afterwards the decrease is rapid. The minimum value for impedance is 1.025 when frequency value is 5.0.

Analysis of $\log (\mathrm{Freq} / \mathrm{Hz}) v s$-phase/deg plot reveals that the value of -phase/deg is zero, when $\log (\mathrm{Freq} / \mathrm{Hz})$ value is 1.0 (Fig. 10). It remains at zero upto $2.522[\log ($ Freq/Hz)]. Afterwards it increases slowly upto 4.0. Then it increases rapidly and reaches a maximum of 68.45 at the frequency value of 5.0.

\section{SS 316 L in Artificial Sweat Solution}

Analysis of $\log (\mathrm{Freq} / \mathrm{Hz})$ vs $\log (\mathrm{Z} / \mathrm{ohm})$ plot reveals that when the value of frequency is 1.0 , the value of impedance $[\log (\mathrm{Z} / \mathrm{ohm})]$ is the highest, namely, 4.799 (Fig. 11). As the value of frequency increases the value of impedance decreases sharply upto the frequency value of $3.5 \mathrm{~Hz}$, when the corresponding impedance value is $3.0 \mathrm{ohm}$. Afterwards the impedance value decreases slowly and reaches a minimum value of $2.4 \mathrm{ohm}$ when the $\log (\mathrm{Freq} / \mathrm{Hz})$ value is 5.0 .

Analysis of $\log ($ Freq $/ \mathrm{Hz}) v s$-phase/deg plot reveals that when $\log$ frequency value is $1.0 \mathrm{~Hz}$, the - phase/deg value is 72.81 (Fig. 12). As the log frequency value increases, it remains constant upto $1.5 \mathrm{~Hz}$. Afterwards it decreases sharply and reaches a minimum value of -phase/deg 30.0 at $\log (\mathrm{Freq} / \mathrm{Hz})$ value of 4.156 . As the value of frequency increases, the value of -phase/deg increases. When $\log$ $($ Freq/Hz) is 5.0, the value of -phase/deg is 66.77 .

Analysis of the $\log (\mathrm{Freq} / \mathrm{Hz})$ vs $\log (\mathrm{Z} / \mathrm{ohm})$ plots is summarized in Table $\mathbf{3}$.

Analysis of the $\log (\mathrm{Freq} / \mathrm{Hz}) \mathrm{s}-$ phase/deg plots is summarized in Table 4.

\section{CONCLUSION}

- $\quad$ Corrosion behaviour of three materials namely, mild steel, mild steel coated with zinc (galvanized steel) and SS $316 \mathrm{~L}$ in artificial sweat has been evaluated by polarization study and AC impedance spectra.

- $\quad$ Polarization study reveals that corrosion resistance of the materials studied, in artificial sweat is GS > SS $316 \mathrm{~L}>$ MS.
- $\mathrm{AC}$ impedance spectra reveal that the corrosion resistance of the materials in artificial sweat is SS 316 $\mathrm{L}>\mathrm{MS}>\mathrm{GS}$.

- $\quad$ AC impedance spectra also reveal that the closepackedness and compactness of the protective film formed on the materials is SS $316 \mathrm{~L}>\mathrm{MS}>\mathrm{GS}$.

- $\quad \mathrm{SS} 316 \mathrm{~L}$ is a better candidate for making ornaments, such as wrist watch, which come in contact with sweat.

Table 3. Analysis of $\log (\mathrm{Freq} / \mathrm{Hz})$ vs $\log (\mathrm{Z} / \mathrm{ohm})$ Plots when Metals are Immersed in Artificial Sweat Solution

\begin{tabular}{|c|c|}
\hline $\log ($ Freq/Hz) & $\log (\mathrm{Z} / \mathrm{ohm})$ \\
\hline \multicolumn{2}{|l|}{ Mild Steel } \\
\hline 1.0 & 2.399 \\
\hline 5.0 & 2.017 \\
\hline 1 to 3 & Remains constant (2.399) \\
\hline \multicolumn{2}{|l|}{ Galvanized Steel } \\
\hline 1.0 & 2.130 \\
\hline 5.0 & 1.025 \\
\hline 1 to 3 & Remains constant (2.130) \\
\hline \multicolumn{2}{|l|}{ SS 316 L } \\
\hline 1.0 & 4.799 \\
\hline 5.0 & 2.4 \\
\hline 1 to 3 & Sharp decrease to 3.0 \\
\hline
\end{tabular}

Table 4. Analysis of Log (Freq/Hz) vs-Phase/Deg Lots, when Metals are Immersed in Artificial Sweat Solution

\begin{tabular}{|c|c|}
\hline \multicolumn{1}{|c|}{$\log ($ Freq/Hz) } & -Phase/Deg \\
\hline \hline Mild steel & \\
\hline 1 to 3 & Zero \\
\hline 3 to 4 & Slow increase \\
\hline 5 & 70.0 \\
\hline Galvanized steel & Zero \\
\hline 1 to 2.522 & Slow increase \\
\hline 2.522 to 4 & 68.45 \\
\hline 5.0 & \\
\hline 1 & \\
\hline 1 to 1.5 & Remains constant 72.81 \\
\hline 1.5 to 4.156 & Sudden decrease to 30.0 \\
\hline 4.156 to 5 & Increases to 66.77 \\
\hline
\end{tabular}




\section{ACKNOWLEDGEMENTS}

The authors are thankful to their respective managements and UGC, India, for their encouragement.

\section{REFERENCES}

[1] Collins KJ. The Corrosion of metal by Palmar Sweat. Br J Ind Med 1957; 14: 191-97.

[2] Iva R, Lidija C, Magdalena U. Metals ion release from electric guitar strings in artificial sweat. Corros Sci 2009; 51: 1985-89.

[3] Song YW, Shan DY, Han EH. Corrosion behaviour of electroless plating Ni-P coatings deposited on magnesium alloys in artificial sweat solution. Electrochim Acta 2007; 53(4): 2009-15.

[4] Jean-Paul R. Corrosion resistance of nickel in artificial sweat and synthetic seawater. Mater Corros 2004; 38(5): 233-36.

[5] Jurij JH, Katherine ER, Howard IM. Oxidative properities of skin exudates - a determinant nickel diffusion: a review. Exog Dermatol 2002; 1(1): 7-17.
[6] Randian JP. Corrosion Behaviour of nickel containing alloys in artificial sweat. J Biomed Mater Res 1988; 22: 649-66.

[7] Hostynek JJ. Corrosion Chemistry of Copper: Formation of potentially skin - diffusible compounds. Exog Dermatol 2004; 3: 263-69.

[8] Arockia SJ, Rajendran S, Ganga SV, John AA, Narayanasamy B. corrosion inhibition by beet root extract. Port Electrochim Acta 2009; 27: 1-11.

[9] Gurappa I. Characterizetia of different materials for corrosion resistance under simulated body fluid conditions. Mater Character 2002; 49:73-79.

[10] http://www.caproco.com/LPR-general-Informatic

[11] Fontana MG. Corrosion engineering. $3^{\text {rd }}$ ed. New Delhi: Tata McGraw-Hiss 2005: pp. 502-03.

[12] Fontana MG. Corrosion engineering. $3^{\text {rd }}$ ed. New Delhi: Tata McGraw-Hiss 2005; p. 298.

Received: January 4, 2010

Revised: February 5, 2010

Accepted: February 25, 2010

(C) Rathish et al.; Licensee Bentham Open.

This is an open access article licensed under the terms of the Creative Commons Attribution Non-Commercial License (http://creativecommons.org/licenses/by$\mathrm{nc} / 3.0 /$ ) which permits unrestricted, non-commercial use, distribution and reproduction in any medium, provided the work is properly cited. 